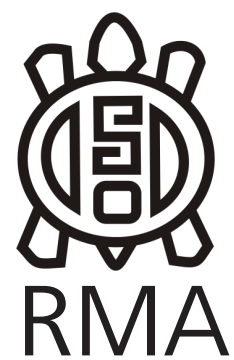

Museología

\title{
El público opina: estudio acerca de la exhibición de restos humanos en el Museo de La Plata
}

\author{
María Marta Reca*, Marina Sardi**, \\ Ana Canzani* y Cecilia Domínguez*
}

*Unidad de Conservación y Exhibición, Facultad de Ciencias Naturales y Museo, Universidad Nacional de La Plata, Argentina. mmreca@fcnym.unlp.edu.ar; **CONICET, División Antropología, Facultad de Ciencias Naturales y Museo.

Universidad Nacional de La Plata, Argentina. msardi@fcnym.unlp.edu.ar

\begin{abstract}
Resumen
La exhibición de restos humanos es un tema controvertido. Cuestiones de índole política, ética y científica unidas a la sensibilidad que acompaña el tratamiento de estos temas genera posiciones encontradas. En este trabajo se evaluaron las opiniones de los visitantes en torno a la exhibición de restos humanos, tomando como referente la exhibición permanente "Ser y Pertenecer: un recorrido por la evolución humana" del Museo de La Plata, inaugurada en el año 2009. Se realizó una encuesta semi-estructurada a 200 individuos en la que se indaga acerca de su perfil sociodemográfico, sus motivaciones y expectativas de la visita, así como sus opiniones acerca de las políticas institucionales de exhibición de restos humanos. Sobre los datos se aplicaron análisis estadisticos (t de Student, Tablas de Contingencia y Prueba de Bondad de Ajuste). Los resultados indicaron que los visitantes mayoritariamente tienen preferencia por la observación de restos humanos, pero paradójicamente acuerdan con la decisión institucional de no exhibir restos de origen americano. Se espera que el estudio contribuya al diseño de una política institucional en materia de exhibiciones que otorgue un lugar significativo a los estudios de público.
\end{abstract}

Palabras claves: museo; políticas de exhibición; restos humanos; encuesta; comunicación

The visitors opine: study about human remains exhibition in the Museo de La Plata

\begin{abstract}
The exhibition of human remains is a controversial subject. Political, ethical and scientific aspects, with the sensitivity are together involved in the debate of this subject, producing contentious positions. In this study, we evaluated visitors' opinions about the exhibition of human remains, considering as reference the permanent exhibition "Being and Belonging: a tour to human evolution", opened in 2009 at the Museo de La Plata. Two hundred people were surveyed through a semi-structured questionnaire, which focuses on socio-demographic aspects, motivations and expectations for visiting the exhibition and their opinions about the institutional policies of human remains exhibition. The information was analyzed by statistical methods (Student's t test, Tables of Contingency and Goodness of Fit). Results indicate that most of the visitors like to observe human remains; however, most of the visitors as well agree with the institutional decision of not to exhibit human remains of American origin. It is expected that this study contributes to develop institutional policies about exhibitions that consider the visitor and its studies as a relevant participant.
\end{abstract}

Keywords: museum, policies of exhibition, human remains, survey, communication

\section{La exposición como comunicación}

Desde hace dos décadas se percibe en los museos una revisión y reformulación de sus formas expositivas bajo un paradigma museológico y museográfico de corte crítico, guiado cada vez más por las necesidades y expectativas del público receptor de la exhibición (Eidelman y Roustan, 2013). De allí que la evaluación y análisis de las formas en que los visitantes interpretan y elaboran los mensajes propuestos constituye una instancia fundamental tanto para la reformulación de las propuestas expositivas, siendo en este caso de carácter correctivo, como para el conocimiento de las motivaciones, expectativas y procesos comunicativos producidos durante la visita, indagando, en este caso, sobre la dimensiones cognitivas y simbólicas.

A su vez, el interés creciente por conocer al destinatario de las exhibiciones se vincula a una concepción más dinámica del patrimonio, en la que convergen múltiples miradas. Como expresa Pérez Santos (2000), históricamente se ha ido operando un cambio en la interpretación de los objetos, por un lado se pasó de la mera valoración estética aislacionista a su consideración como signo 
de funciones culturales. Por otro, en la concepción del visitante, de destinatario pasivo del discurso expositivo a sujeto activo y parte integrante de la exposición misma. Consecuentemente, se experimenta una transformación en la conceptualización de la exposición, transitándose de la mera exhibición de objetos (exposición contemplativa) a una forma de comunicación con características específicas (exposición interactiva).

Esta transformación implica un desplazamiento conceptual del museo que exhibe colecciones al museo que comunica, de una idea de público general indiferenciado hacia un público heterogéneo con competencia e intereses diversos. Desde este modelo se busca establecer una mejor interacción entre el mundo del visitante y la propuesta del museo.

En relación a las exhibiciones antropológicas, el discurso museológico acerca de la representación del conocimiento de "otras culturas" responde, en distintos momentos, a formas particulares de entender la configuración de las colecciones, su distribución en el espacio expositivo, la disposición de los objetos al interior de la vitrina, su articulación con otros recursos que acompañan su "puesta en escena". Se suman a estas consideraciones museográficas las ideas vigentes sobre el otro cultural, la intención de los curadores hacia los visitantes (mensajes) así como la concepción acerca de los modos de apropiación del conocimiento. Finalmente, el diseño de una política institucional, el momento histórico en que se gesta, y las condiciones materiales de su producción impactan en el resultado final. Desde un punto de vista semiótico, el conjunto de significaciones de las que será investido un objeto de colección se encuentra anclado en la entramada red de relaciones de sentido establecidas en un contexto particular para determinado conjunto de intérpretes y en el marco de una comunidad dada (Magariños de Morentín, 2008). Se asume entonces que este tipo de exhibiciones está inevitablemente organizado en base a supuestos acerca de las intenciones de los productores de los objetos, las habilidades y de la audiencia, las pretensiones de autoridad sobre el tema que tenga la exhibición y los juicios sobre el mérito estético o la autenticidad de los objetos o entornos exhibidos (Karp 1991). En este marco, el patrimonio ingresa en ámbitos dinámicos de debate político y social, transformándose en un conjunto de bienes sobre los cuales ejercer un derecho (Reca 2011).

\section{Las colecciones de restos humanos y los museos de ciencias naturales}

Hacia fines del siglo XIX, el gobierno del naciente estado argentino, en busca de consolidar el control económico de su territorio, organizó expediciones militares y científicas (Farro 2009; Podgorny 1999; 2008; Podgorny y Lopes 2008), culminando con la guerra contra las poblaciones indígenas, Ilamada Conquista del Desierto. En dichas misiones se recolectaban objetos naturales y culturales y, además, los restos de aborígenes recientemente muertos (Zeballos [1881] 1960), siguiendo procedimientos similares a los de otros países (Alberti 2008). Contemporáneamente, se formaron los primeros museos, tales como el Museo de La Plata y Museo Etnográfico de Buenos Aires donde se albergaban y exhibían los objetos recolectados en dichas misiones (Podgorny 2008).

Las colecciones antropológicas estaban formadas por individuos nativos americanos y compuestas, principalmente, por sus cráneos (Lehmann-Nitsche 1910). Otras colecciones se formaron a partir de la compra, donación de colecciones privadas e intercambio con instituciones extranjeras, aumentando así su diversidad (Farro 2009). En el Museo de La Plata una parte menor de las colecciones, aunque representativa del paradigma dominante, se formó por aborígenes que murieron en dicha institución luego de ser capturados durante la Conquista del Desierto (Lehmann-Nitsche 1910). La constitución de colecciones de este tipo continuó a lo largo del siglo XX, aunque cambiaron los procedimientos. Los restos humanos obtenidos por estos métodos formaron parte de la historia natural representada en los museos (Alberti 2008).

El interés en la exhibición e investigación de los restos humanos y en la observación, por parte de los visitantes, se asume vinculado al conocimiento de la historia humana y a la reflexión sobre uno mismo y de la propia mortalidad.

En las últimas décadas, en numerosos países la autoridad científica sobre los muertos es objeto de debate frente a las denuncias y los reclamos por parte de comunidades descendientes de pueblos originarios que, en forma explícita, otorgan a estos materiales una vinculación ancestral e incluso son motivo de prácticas rituales. Comenzó así a operarse un cambio en el modo en que los restos humanos son tratados dentro de los museos. En Argentina se promulgó la Ley Nacional 25.517 (2001) que trata sobre los restos humanos de aborígenes americanos que forman parte de colecciones públicas o privadas. Dicha ley afirma, en su artículo 1 que "Los restos mortales de aborígenes, cualquiera fuera su característica étnica, que formen parte de museos y/o colecciones públicas o privadas, deberán ser puestos a disposición de los pueblos indígenas y/o comunidades de pertenencia que lo reclamen." Y, en su artículo 3, enuncia que "Para realizarse todo emprendimiento científico que tenga por objeto a las comunidades aborígenes, incluyendo su patrimonio histórico y cultural, deberá contar con el expreso consentimiento de las comunidades interesadas".

En el Museo de La Plata se realizó, mediando leyes nacionales que lo ordenaron, la restitución de los restos de los Caciques Inakayal a la comunidad de Tecka (Chubut, Argentina) en 1994 (Politis, 1994; Sardi, 2011) y de Panquitruz Gner, conocido como Mariano Rosas, a la comunidad de Leuvucó (La Pampa, Argentina) en 2001. 
En 2010 se restituyó el cráneo de una niña conocida como Damiana y de otro individuo a la comunidad Aché (Paraguay) (Ametrano, 2010; Arenas, 2011; Endere, 2011) y han continuado las gestiones con comunidades de Tierra del Fuego (Argentina). Paralelamente, se acondicionaron depósitos y se renovaron las exhibiciones.

\section{La evolución y la muerte en Ser y Pertenecer}

La sala de exhibición permanente de antropología biológica del Museo de La Plata bajo el título "Ser y pertenecer: un recorrido por la evolución humana" (SyP) fue inaugurada en marzo de 2009. Uno de los principales factores que gestaron la intervención de la sala de exhibición fue el retiro de los restos humanos de origen americano. Más de la mitad de sus 44 vitrinas contenían esqueletos, cráneos y cuerpos momificados de dicha procedencia. A partir de las solicitudes explícitas de organizaciones de pueblos originarios, la Facultad de Ciencias Naturales y Museo (Universidad Nacional de La Plata), luego de un rico debate con actores institucionales del área de la antropología y atendiendo a las recomendaciones del código de ética del ICOM, que califica a los restos humanos como "materiales delicados", resolvió proceder al retiro de exhibición de los restos humanos de origen americano'

Otros antecedentes sobre el tema fueron fuente de inspiración para tomar esta medida. Entre ellos pueden citarse los convenios sobre el tratamiento de restos humanos tales como el Congreso Mundial de Arqueología de Dakota del Sur en 1989 con el acuerdo de Vermillion. En Argentina, la declaración de Río Cuarto en el marco del Primer Foro Pueblos Originarios-Arqueólogos (2005), los criterios sobre la exhibición de restos humanos en los museos expuestos por la Dirección Nacional de Patrimonio y Museos de la Secretaría de Cultura de la Nación (2006) y la Declaración de la Asociación de Antropología Biológica Argentina ( $A A B A)$ en relación con la ética del estudio de restos humanos (Salta - 2007).

La renovación de SyP involucró aspectos tanto de carácter museográfico como conceptuales. El nuevo guión de exhibición se desarrolla según un hilo conductor que contempla temas como la evolución humana en sus aspectos tanto filogenéticos como ontogenéticos y la diversidad (Pucciarelli y Sardi 2009; Sardi 2009), a saber: 1- El hombre como un primate, donde se mencionan las características que tienen en común los primates. 2- El linaje humano, donde se describe la diversidad de

12006- Resolución del Consejo Académico de la Facultad de Ciencias Naturales y Museo- UNLP - Retirar los restos humanos en exhibición garantizando su condiciones de preservación y documentación- Desarrollar una estrategia de vinculación con el público a través de la elaboración de mensajes claros y educativos de modo que las acciones no se agoten en la ausencia de las piezas en la sala, sino que reflejen una política institucional y sean, a su vez, generadores de reflexión sobre el tema. Atender a los reclamos de restitución de restos (Ley 25.517) de manera de favorecer una política de cogestión con las comunidades, y las instituciones que los representan, en el marco de un programa riguroso. especies homínidas, y los principales eventos evolutivos y sus causas, las tendencias de cambio en el linaje humano y los aspectos que constituyeron la condición humana. 3- La diversidad entre las poblaciones y entre individuos dentro de la especie humana, donde se explican los mecanismos de cambio, los que son heredados así como los adquiridos.

A través de la presentación de réplicas de partes esqueletarias, de restos humanos no americanos, videos, diagramas e interactivos (v.g. cerebro y lenguaje, índice de masa corporal) se pone de manifiesto la complejidad del proceso evolutivo y de las evidencias con las que se construye el conocimiento científico, la singularidad humana, así como el parentesco entre especies, siendo intención a lo largo de toda la exhibición involucrar al visitante en los procesos mencionados. Así, a medida que se recorre SyP temporalmente y conceptualmente se desplaza de lo lejano a lo cercano, de lo común entre los seres humanos a lo particular, manifestado en la diversidad humana.

Dando cierre al recorrido y como expresión de dicha diversidad, el último sector, dedicado a las prácticas y representaciones en torno a la muerte, presenta una momia de la cultura guanche procedente de las Islas Canarias y un paquete funerario procedente de Egipto. Completan el contexto expositivo, macroleyendas y un video en el que se pone de manifiesto la diversidad de prácticas en torno a la muerte y los muertos en distintas sociedades y se explican las políticas institucionales de retiro de los restos de origen americano. El objetivo de este último sector fue: a- superar el estatus de "objeto" del resto humano para recuperar el de sujeto/ persona/ancestro; b- presentar el valor científico de los restos humanos como objeto de estudio y su aporte al conocimiento antropológico; c- incorporar posiciones opuestas acerca de su exhibición explicitando el pedido, por parte de pueblos originarios, del retiro de exhibición y d-informar acerca de las leyes que regulan y garantizan la restitución de los restos identificados y los códigos de ética planteados para el tratamiento de los materiales delicados.

\section{El público opina}

Las exhibiciones poseen una fuerza educativa considerable y pueden ser pensadas como un caso especial de comunicación en masa, pues comparte con esta el número elevado de receptores (los visitantes) y la ausencia del intercambio personal entre el emisor (los curadores) y el receptor. Conscientes que produce diferentes y nuevos efectos de significación y acciones de interpretación según las competencias cognitivas y simbólicas de los receptores.

Se acepta que cada visitante se conecta de modo diferencial con la exhibición, su percepción es selectiva, de modo que en él recae una parte considerable de responsabilidad 
en la producción de nuevas síntesis cognitivas. Todo visitante trae consigo un universo cultural, expectativas, necesidades, percepciones y prácticas, que se activan en la visita concebida como experiencia situada. El visitante, ante la propuesta comunicativa de la exposición, activa una serie de hábitos cognitivos, competencias culturales previas que le permiten interpretar el patrimonio cultural. Éste selecciona una de las múltiples estrategias posibles de recorrido, evoca una secuencia de signos de acuerdo a "una disposición de su mente" y a partir de ello, se identifica, considera ajeno, se sorprende, ignora o rechaza lo propuesto por el despliegue expositivo. Para esto es necesario dar mayor espacio al protagonismo, la interacción y el espíritu crítico, de modo de promover un aprendizaje significativo, en el sentido que los nuevos contenidos se incorporan de modo no arbitrario, conectándose con estructuras pre-existentes (Asensio 1996). El visitante activa su capital cultural, concebido por Bourdieu y Wacquant(1995) como el conjunto de saberes y disposiciones adquiridas socialmente que permiten producir y reproducir las estrategias de acción y apropiación.

La riqueza de los mensajes propuestos reside en la multiplicidad de lecturas que atraviesan la experiencia de la visita, generando un campo de análisis complejo. Los estudios de las diferentes modalidades de su percepción/ interpretación, tanto en las instancias de la recepción del público como de la producción por los expertos, no son un área solo de interés académico. Son un área crucial en la gestión del patrimonio cultural y la planificación de las nuevas funciones de los museos en el mundo contemporáneo (Cousillas 1997).

Por diversas fuentes, formales e informales, se sabe que los cuerpos momificados y los restos humanos son uno de los principales atractivos para el público general, e incluso que un porcentaje no despreciable asiste al museo motivado por este tipo de "curiosidades" (Brooks y Rumsey 2007, Kilmister 2003, Korn et al. 1999), de manera que su retiro en el Museo de la Plata produjo, sin lugar a dudas, un impacto importante. En este contexto, el objetivo de este trabajo es conocer las opiniones de los visitantes de la exhibición "Ser y pertenecer, un recorrido por la evolución humana" acerca de las nuevas políticas sobre la exhibición de restos humanos. Para esto, se consideraron aspectos tales como las motivaciones de la visita, las preferencias de contenidos, el conocimiento previo de las leyes y las opiniones acerca del retiro de la exhibición de los restos humanos de origen americano. El propósito de este relevamiento es el de vincular las distintas variables que potencialmente se relacionan a la recepción de las nuevas políticas.

\section{Material y métodos}

El relevamiento de la información se realizó a través de una encuesta semi-estructurada. La muestra se obtuvo de 200 visitantes (98 mujeres y 102 hombres) que asistieron al Museo de La Plata y que realizaron la visita sin guías, una vez que finalizaron el recorrido propuesto en la exhibición.

Las encuestas se realizaron de junio a noviembre de 2011 y en junio de 2012, durante 24 días, de los cuales 19 fueron días de semana, además de 5 sábados. De acuerdo con los registros obtenidos de la venta de entradas, que no incluye niños menores de 12 años ni grupos escolares ni visitantes durante vacaciones de invierno (grupos no relevados), se estimó la cantidad de personas que visitaron el museo. Se calculó que de martes a viernes durante los meses en que se realizó la encuesta ingresaron al museo en promedio 280 visitantes por día, en tanto que los sábados la cantidad promedio de visitantes diarios fue de 580. Si bien las 200 personas encuestadas representan una proporción baja respecto del total, cabe considerar que ese total contempla el ingreso de numerosos grupos familiares y la encuesta se realizó a solo un miembro de cada grupo y no incluyó a menores de 14 años. Por otro lado, no todos los visitantes que ingresan al museo recorrieron SyP y no todos aceptaron participar de la encuesta.

La encuesta comprende preguntas cerradas y otras abiertas. Su objetivo fue obtener información acerca de: a) el perfil socio-demográfico de los visitantes encuestados, b) las motivaciones para conocer la sala SyP, las preferencias y gustos respecto de los contenidos de la sala SyP y c) las opiniones respecto de la políticas institucionales acerca de la exhibición de restos humanos. Si bien la encuesta cuenta con un mayor número de rasgos relevados, los evaluados en este estudio fueron derivados de las preguntas que aparecen en la Tabla 1.

Muchas preguntas, de carácter abierto, tuvieron como resultado una gran amplitud de respuestas. Ante esta diversidad, fue necesario definir y agrupar la información en categorías inclusivas. Esto otorgó mayor inteligibilidad a los resultados y, además, permitió su adecuación a los métodos estadísticos.

Las respuestas obtenidas de la pregunta ¿Qué lo motivó a visitar esta exhibición? (Tabla 1) se agruparon en tres categorías: visita, cognición y expectativa. Las respuestas se clasificaron en alguna categoría según la prioridad que el visitante le dio al ser encuestado. En "visita" el encuestado aludió a una circunstancia de sociabilidad vinculada al paseo, la compañía (traer a los niños, etc.), la recomendación e invitación. Se incluye la circunstancia fortuita de estar en el museo cuando la respuesta fue claramente referenciada en la sala. En "cognición" el visitante refirió a una actitud motivada por el conocer, aprender, comprender, estudiar, y a un sentimiento como el de curiosidad, gusto y descubrimiento. En "expectativa" el visitante mencionó una experiencia de visita anterior $y$, en consecuencia, la respuesta se refiere a conocer lo nuevo, los cambios, a sentimientos de nostalgia y recuerdos. También, cuando se refirió al conocimiento de 
Tabla 1. Preguntas efectuadas a los visitantes

Table 1. Questions requested to visitors

\begin{tabular}{l}
\hline a) Perfil del visitante \\
\hline Sexo \\
Edad \\
Lugar de procedencia/residencia \\
Nivel de instrucci?n (estudios completos) \\
QCómo realiza la visita? Se considera si realiza la visita a) con la familia, b) con amigos, c) con un \\
contingente, d) en pareja o f) solo \\
\hline b) Sondeo de opinión acerca de los contenidos de la exhibición SyP \\
\hline ?Es la primera vez que visita la exhibición? \\
? Qué lo motivó a visitar esta exhibición? \\
?Qué le llamó la atención de la exhibición? \\
c) Sondeo de opinión acerca de las políticas institucionales de exhibición de restos humanos \\
\hline Antes de la visita ?conocía la ley de restitución de restos humanos pertenecientes a comunidades \\
originarias? \\
?Qué piensa de la decisión de no exponer restos humanos de origen americano?
\end{tabular}

un tema u objeto en particular. Estas categorías no son excluyentes en la experiencia de la visita. Es importante aclarar que, en la mayoría de los casos, no fue posible distinguir claramente si el visitante menciona la sala o el museo en general. Esto es así respecto de la categoría visita, resultando más claro en la categoría expectativa, al nombrar objeto o temas específicos.

Las respuestas obtenidas de la pregunta ¿Qué le llamó la atención de la exhibición? (Tabla 1) se agruparon en cuatro categorías, según se aluda a objetos, temas, experiencia interactiva y puesta museográfica que incluye tanto aspectos constructivos como conceptuales. En "objetos" se clasificaron las preferencias por las momias, esqueletos, cráneos, fósiles, piezas mortuorias y Venus de Millendorf, entre otros. En "tema" se agruparon menciones por la evolución, adaptación, alimentación, árbol filogenético, culturas antiguas, paleontología, diversidad, cerebro, deformaciones craneales y modificaciones corporales, entre otros. En "interactivos" se agruparon las preferencias por los videos, pantallas interactivas y cálculo del índice de masa corporal (IMC), entre otros. En "puesta museográfica" se agruparon los gustos por infografías, cartelería, estructura, presentación, limpieza, diagrama, didáctica, cantidad de información, pedagogía, organización espacial y temporal. Otras categorías son: "todo", cuando el visitante indica que todo le llamó la atención, y "nada" cuando nada en particular atrajo su atención.

Para cada categoría se calcularon los porcentajes. Adicionalmente, se obtuvo el margen de error (e) para el $95 \%$ de confianza de los porcentajes calculados. Este valor mide la diferencia máxima que se espera tener entre un resultado obtenido a partir de una muestra y su valor poblacional verdadero (Kelmanski, 2009). Se calculó como: e $=$ z. $\sqrt{ }($ p.q $) / \sqrt{ }$, donde $z$ es el nivel de confianza habitual de 1,96 que significa que dicho margen de error será válido un $95 \%$ de las veces que se calcule un estimador; p.q se obtuvo como 0,5 que representa la máxima variación de las respuestas. Por ello, e $=0,98 / \sqrt{ } 200=0.069$, o sea un valor aproximado de $7 \%$. La utilidad de este valor se verifica cuando se utilizan muestras de bajo $n$ permitiendo con un alto grado de confianza extrapolar los resultados a la población, midiendo la diferencia máxima que se espera tener entre un resultado obtenido a partir de una muestra y su valor poblacional verdadero (Kelmansky, 2009). Este valor se consideró relevante en relación a las opiniones respecto de la exhibición y de las políticas institucionales.

El análisis de los datos se realizó a través de métodos estadísticos. Cuando se analizaron frecuencias de distintas categorías sin subdividir la muestra se realizó la prueba de Bondad de Ajuste. La hipótesis nula se basó en el modelo de distribución teórica uniforme bajo el supuesto de que todas las categorías están igualmente representadas y se probó mediante el cálculo de un valor chi-cuadrado ( 2 ) (Zar 1999). Este modelo permite identificar si existe alguna categoría con mayor frecuencia respecto de otras.

En aquellos casos en que la muestra fue subdividida y se compararon variables categóricas, las frecuencias se compararon en las sub-muestras por medio de Tablas de Contingencia. El principal criterio de subdivisión fue el sexo. La hipótesis nula se basa en un modelo teórico de distribución independiente de los datos y se probó mediante el cálculo de un valor chi-cuadrado $(\chi 2)$ de Pearson (Zar 1999). Cuando se compararon tablas de un grado de libertad se realizaron los ajustes pertinentes. Esta prueba permite establecer si hay relaciones significativas entre las variables. Por ejemplo, permite identificar la eventual relación entre variables socio-demográficas y las opiniones sobre algún ítem de la encuesta. En aquellos casos en que se analizaron variables cuantitativas (por ejemplo, la edad) entre dos sub-muestras se utilizó la prueba de t de Student (Zar 1999). La hipótesis nula se basa en la igualdad de promedios entre muestras. En todas las pruebas los valores de probabilidad para el rechazo de hipótesis se establecieron en 0,05 y 0,01. 
Los análisis estadísticos se realizaron con el programa Systat 10.2.

\section{Resultados}

Perfil de los visitantes

De las 200 personas encuestadas, más del 90\% tiene más de 20 años. Los individuos de distintos sexo se distribuyen en las categorías etarias con algunas diferencias (Tabla 2). La edad en los hombres (media $=35,9 \pm 13,1$ ) es mayor a la edad de las mujeres (media $=31,5 \pm 12,8$ ) y su diferencia resultó significativa $(t=2,35$; grados de libertad = 198; probabilidad =0,019).

La procedencia de los visitantes se refiere a la localidad, provincia o país en que reside y se agruparon en grandes categorías. Éstas difieren de modo altamente significativo $(\chi 2=73,75$; grados de libertad $=4$; probabilidad $<0,01)$. El 55\% procede de la ciudad de La Plata y localidades geográficamente cercanas (Gran La Plata, Buenos Aires y Gran Buenos Aires) (Tabla 3). Sin embargo, no hubo diferencias entre sexos en cuanto a la procedencia $(\chi 2=$ 1,07; grados de libertad $=3$; probabilidad $<0,784)$. En esta tabla de contingencia la categoría correspondiente a los visitantes de Norteamérica y Europa fue eliminada por presentar frecuencias esperadas menores a 5.

Para determinar el nivel de instrucción se consideraron los estudios completos. Los visitantes no se distribuyeron de modo uniforme $(\chi 2=50,6$; grados de libertad = 3; probabilidad $<0,01)$, siendo que más del $46 \%$ solo han completado el nivel medio, aunque una proporción importante de ellos son estudiantes de niveles terciario o universitario (Tabla 4). La distribución por sexos del nivel de instrucción no difiere $(\chi 2=3,78$; grados de libertad $=$ 3; probabilidad $=0,285$ ).

La mayoría de los visitantes asisten a la exhibición acompañados, principalmente en familia (Tabla 5). Las distintas categorías difieren de modo altamente significativo $(\chi 2=99,15$; grados de libertad $=4$; probabilidad $<0,01)$.

A partir de los resultados fue posible caracterizar el perfil

\begin{tabular}{lrr}
\hline Grupo etario & mujeres & hombres \\
\hline$<20(n=19)$ & 12,2 & 6,8 \\
$20<30(n=78)$ & 44,9 & 33,3 \\
$30<40(n=45)$ & 18,3 & 26,4 \\
$40<50(n=29)$ & 11,2 & 17,6 \\
$50<60(n=19)$ & 10,2 & 9,0 \\
$\geq 60(n=10)$ & 3,0 & 6,8 \\
\hline
\end{tabular}

Tabla 2. Porcentaje de visitantes clasificados por sexo y grupo de edad $(n=200)$

Table 2. Percentage of visitors classified by sex and age class $(n=200)$

\begin{tabular}{lccc}
\hline Residencia & Total & M ujeres & Hombres \\
\hline La Plata y Gran La Plata & 21,0 & 19,4 & 22,5 \\
Buenos Aires y Gran & 34,0 & 35,7 & 32,3 \\
Buenos Aires & 32,0 & 30,6 & 33,3 \\
Resto de Argentina & 10,5 & 12,2 & 8,8 \\
Sudamérica & 2,5 & 2,0 & 2,9 \\
\hline Norteamérica y Europa*
\end{tabular}

*categoría excluida del cálculo de $\chi^{2}$

Tabla 3. Porcentaje de visitantes clasificados según su procedencia (n $=200$ )

Table 3. Percentage of visitors classified by residence $(n=200)$

\begin{tabular}{llll}
\hline Nivel & Total & Mujeres & Hombres \\
\hline Primario $(n=34)$ & 17,0 & 17,3 & 16,6 \\
M edio $(n=93)$ & 46,5 & 42,8 & 50,0 \\
Terciario $(n=31)$ & 15,5 & 20,4 & 10,8 \\
Universitario $(n=42)$ & 21,0 & 19,4 & 22,5 \\
\hline
\end{tabular}

Tabla 4. Porcentaje de visitantes clasificados por sexo y nivel educativo $(n=200)$

Table 4. Percentage of visitors classified by sex and educative level ( $n$ $=200$ )

de los visitantes encuestados. Si bien se distribuyen igualmente por sexos, las mujeres que componen la muestra son más jóvenes que los hombres. Se trata, en general, de personas que han completado sus estudios de nivel medio y muchos cursan o han cursado estudios superiores. La mayoría viene de la ciudad de La Plata y localidades próximas.

\section{Opiniones sobre la exhibición Ser y Pertenecer}

El $61 \%$ de los visitantes manifestó que visitaba la exhibición por primera vez. Respecto de las motivaciones para observar la exhibición, las distintas categorías se distribuyeron de modo muy desigual (Tabla 6), con diferencias altamente significativas $(\chi 2=261,72$; grados de libertad =5; probabilidad <0,01). El 51,5\% manifestó que su motivación fue realizar la visita, con un margen de error entre 44,5 y 58,5\%. Para otros se vinculó a aspectos

\begin{tabular}{ll}
\hline Modo & Porcentaje \\
\hline Grupo familiar & 45,5 \\
Grupo de amigos & 16,0 \\
Contingente & 7,0 \\
En pareja & 23,5 \\
Solo & 8,0 \\
\hline
\end{tabular}

Tabla 5. Porcentaje de visitantes según modo en que realizan la visita $(n=200)$

Table 5. Percentage of visitors according to the way for doing the visit $(n=200)$ 
relativos a la cognición $(18,5 \% \pm 7)$ y las expectativas $(14,5 \% \pm 7)$, revelando un solapamiento en estas últimas categorías.

Frente a la pregunta acerca de qué fue lo que más le llamó la atención de la sala, los visitantes tuvieron la posibilidad de mencionar más de un ítem, aunque la mayoría solo mencionó uno. En total realizaron 222 menciones. En este caso el margen de error calculado se ajustó a la cantidad de ítems comparados. Dado que era una pregunta abierta, los visitantes ofrecieron respuestas diversas y las mismas se reagruparon en categorías mayores. Las distintas categorías (Tabla 7) aparecen representadas con diferencias altamente significativas $(\chi 2=275,27$; grados de libertad $=5$; probabilidad $<0,01)$. La categoría predominante es aquella en la que se mencionan objetos de la exhibición (Tabla 7), con un 53,1\%, cuyo margen de error entre 46,1 y 60,1\% no se superpone con ninguna otra categoría. La misma incluye las momias, siendo explícitamente mencionadas en 64 oportunidades. Esto representa el $54 \%$ respecto de otros objetos (64/118). Notablemente, otros objetos frecuentemente mencionados son los cráneos y esqueletos, muy relacionados a las momias, que se presentaron en 45 oportunidades. Siendo que dos visitantes mencionaron simultáneamente a las momias y a los esqueletos, se considera que los restos humanos -momificados o no- predominan ampliamente entre los ítems que más llamaron la atención de la exhibición, siendo el 90\% (107/118), con un margen de error entre 81 y 99\%. En 57 oportunidades $(25,6 \% \pm 6,5)$ se mencionaron temas de la exhibición (Tabla 7). Entre ellos están: evolución, alimentación, diversidad, adaptación, paleontología, modificación, desnutrición, cerebro, pigmentación. La referencia acerca de la evolución fue predominante, con el $44 \%$ de las menciones. El 62,5\% 7 , de los visitantes calificó SyP como muy buena, el 35,5\% como buena y el 2\% la calificó como regular.

Opiniones sobre las políticas de retiro de la exhibición de restos de origen americano

Antes de conocer la opinión de los visitantes se consultó acerca de su conocimiento de la Ley 25.517 de restitución

\begin{tabular}{ll}
\hline Categorías & Porcentaje \\
\hline Visita & 51,5 \\
Cognición & 18,5 \\
Visita y cognición & 14,5 \\
Expectativa & 8,0 \\
Expectativa y visita & 2,0 \\
Expectativa y cognición & 5,0 \\
Visita, cognición y expectativa & 0,5 \\
\hline
\end{tabular}

Tabla 6. Porcentaje de motivaciones para visitar la exhibición $(n=200)$

Table 6. Percentage of motivations for doing the visit $(n=200)$

\begin{tabular}{lr}
\hline Categoría & Porcentaje \\
\hline Temas & 25,6 \\
Objetos & 53,1 \\
Interactivos & 8,1 \\
Puesta museográfica & 5,4 \\
Todo & 4,9 \\
Nada & 2,7 \\
\hline
\end{tabular}

Tabla 7. Porcentaje de ítems preferidos por los visitantes $(n=222)$

Table 7. Percentage of preferences of visitors $(n=222)$

de restos humanos pertenecientes a pueblos originarios. El 80,5\% la desconocía.

Ante la pregunta “¿Qué piensa sobre la decisión de no exponer restos humanos de origen americano?" hubo una diferencia significativa en las opiniones $(\chi 2=93,13$; grados de libertad $=2$; probabilidad $<0,01)$. El $62,5 \%$ de los visitantes, con margen de error entre 55,5 y $69,5 \%$, manifestaron estar de acuerdo con la decisión institucional (Tabla 8). El 30,5\% 7 manifestó desacuerdo por la decisión, en tanto que el $7 \%$ no contestó o contestó que no tenía interés en el tema. Los márgenes de error calculados no se superponen entre quienes estuvieron a favor y en contra de las políticas de exhibición.

Las ulteriores comparaciones estadísticas se realizaron considerando solamente aquellos que tomaron posición sobre las políticas institucionales $(n=186)$. Cuando el acuerdo/desacuerdo con las políticas de retiro se cruzaron en relación al sexo no se observaron diferencias significativas ( $\chi 2$ con la corrección de Yates $=0,17$; grados de libertad $=1$; probabilidad $=0,678$ ) (Tabla 8). Cuando se comparó respecto del nivel de instrucción tampoco hubo diferencias significativas ( $\chi 2=6,40$; grados de libertad $=1$; probabilidad $=0,094)$ (Tabla 9). La comparación de la edad en las muestras de individuos que acuerdan con el retiro y los que no acuerdan indicó que no difieren significativamente $(t=1,51$; grados de libertad $=184$; probabilidad $=0,133$ ).

Es esperable que los visitantes que manifestaron preferencia por los restos humanos expresaran desacuerdo

\begin{tabular}{lccc}
\hline \multicolumn{1}{c}{ Opinión } & Total & Mujeres & Hombres \\
\hline De acuerdo $(n=125)$ & 62,5 & 61,2 & 63,7 \\
No está de acuerdo $(n=61)$ & 30,5 & 32,6 & 28,4 \\
$\begin{array}{l}\text { No le interesa/no contesta } \\
(n=14)^{*}\end{array}$ & 7,0 & 6,1 & 7,8 \\
\hline
\end{tabular}

*categoría excluida del cálculo de x2

Tabla 8. Porcentaje de opiniones sobre la política de exhibición de restos humanos clasificados por sexo de los visitantes $(n=200)$

Table 8. Percentage of opinions about policies for human remains exhibition classified by the sex of visitors $(n=200)$ 


\begin{tabular}{lllll}
\hline Opinión & Primario & Secundario & Terciario & Universitario \\
\hline De acuerdo $(n=125)$ & 41,2 & 63,4 & 67,7 & 73,8 \\
No está de acuerdo $(n=61)$ & 44,1 & 30,1 & 25,8 & 23,8 \\
No le interesa/no contesta $(n=14)$ & 14,7 & 6,5 & 6,4 & 2,4 \\
\hline
\end{tabular}

Tabla 9. Porcentaje de opiniones sobre la política de exhibición de restos humanos clasificados por nivel de instrucción de los visitantes ( $\mathrm{n}=200$ )

Table 9. Percentage of opinions about policies for human remains exhibition classified by the educative levels of visitors $(n=200)$

con el retiro de aquellos de origen americano. Por ello, se comparó esta sub-muestra de 107 individuos con los 93 visitantes que tuvieron preferencias diferentes a la de los restos humanos a fin de conocer si hay dependencia respecto de las políticas de exhibición. En la Tabla 10 se observan las frecuencias y los porcentajes. Los márgenes de error calculados se ajustaron a cada n (107 y 93) y revelan que, aún siendo mayores, los porcentajes de opiniones a favor y en contra de las políticas de exhibición tampoco se superponen. Es posible observar que entre los visitantes que mostraron preferencias por los restos humanos el desacuerdo con las políticas institucionales es mayor que entre los restantes visitantes (Tabla 10). Sin embargo, la prueba de independencia indicó que los datos se distribuyen al azar $(\chi 2=1,50$; grados de libertad $=2$; probabilidad $=0,471$ ); es decir, las diferencias entre ambos grupos no son significativas.

\section{Discusión y conclusión}

El manejo de restos humanos en los museos decimonónicos, como el Museo de La Plata, es un tema controversial a la luz de las prácticas con las que gran parte de esas colecciones fueron formadas. Si bien estas prácticas y conjuntamente la adquisición de datos cambiaron notablemente entre los siglos XIX y XXI, la administración de los restos humanos que aún se encuentran en los museos requiere de una constante toma de decisiones éticas.

En las últimas décadas se han publicado muchos de esos debates y recomendaciones (Alberti et al. 2009; Cassman et al. 2007; Lohman y Goodnow 2006; van Duuren 2007), en las que se pone en evidencia las dificultades de realizar propuestas concluyentes, dada la complejidad del tema y la diversidad de contextos socio-históricos y políticos en los que se inserta la institución museo.

Sin duda, la toma de decisiones sobre la exhibición o no de los restos humanos involucra una gran cantidad de profesionales y de actores sociales. Este trabajo se focalizó en uno de esos actores, los visitantes, y se circunscribió a aquellos que visitaron la exhibición sobre evolución humana, en el contexto de un museo de ciencias naturales.

Cuando el visitante recorre las salas respetando el sentido sugerido, antes de llegar -en la planta alta del edificio- al tema de la evolución humana, junto con la diversidad cultural pasada y presente, éste ha tomado contacto -en la planta baja- con restos de animales invertebrados y vertebrados, actuales y fósiles, réplicas de algunos especímenes y animales embalsamados. En tanto que los seres humanos están emparentados con otros seres vivos (Sardi 2009), los restos humanos aparecen, así "naturalizados" junto con los restos de otras especies biológicas.

A partir del análisis de las motivaciones para conocer la exhibición SyP, la mayoría recorrió la sala como parte de la visita general al museo o simplemente motivados por la realización de un paseo. Hubo visitantes que expresaron su deseo de "conocer" y "aprender" (Tabla 6). Esto significa que los visitantes no mostraron una motivación particular vinculada con la exhibición SyP o con parte de sus contenidos.

Luego de realizada la visita, las preferencias y los gustos de los encuestados se concentraron mayormente en algún tipo de objeto (Tabla 7) y una gran proporción de visitantes mostró interés por los restos humanos, sean momificados o no. Ante estos resultados, cabe

\begin{tabular}{llll}
\hline Opinión & Rhs & Otra & Total \\
\hline De acuerdo & $63(59,0 \pm 9,4)$ & $62(66,6 \pm 10)$ & 125 \\
No está de acuerdo & $35(32,7 \pm 9,4)$ & $26(27,9 \pm 10)$ & 61 \\
No le interesa/no contesta & $9(8,4 \pm 9,4)$ & $5(5,4 \pm 10)$ & 14 \\
Total & $107(100)$ & $93(100)$ & 200 \\
\hline
\end{tabular}

Tabla 10. Frecuencias (y porcentajes \pm error) de opiniones sobre las políticas de exhibición de visitantes clasificados según las preferencias por los restos humanos (rhs) u otra preferencia (otra)

Table 10. Frequencies (and percentages \pm error) of opinions about policies for human remains exhibition classified according to the preferences of visitors for human remains (rhs) or another preference (otra) 
preguntarse si este interés está directamente relacionado con el hecho de que la nueva exhibición contiene una gran proporción de cráneos, esqueletos y otros ejemplares similares provocando, en una primera intención, una respuesta vinculante. Sin embargo, en SyP solo se exhibe una momia y un paquete funerario, que fueron mencionados en 64 ocasiones, frente a las 45 que se mencionaron "cráneos", "esqueletos", "fósiles", etc. Por esto, se descarta que la prevalencia de este tipo de objetos sea la causa directa de la preferencia por parte del público, más aún considerando que otros estudios realizados en situaciones muy diferentes (Brooks y Rumsey 2007; Kilmister 2003; Korn et al. 1999) observaron también que el público manifiesta preponderantemente curiosidad por la observación de restos humanos. Cabe destacar que gran parte de los objetos exhibidos en SyP no son huesos reales sino réplicas dado que se representan fósiles de primates o de homínidos. Cuando se representan poblaciones modernas, se muestran distintos aspectos a partir de restos esqueléticos de individuos no americanos, pero cuando no fue posible se realizaron réplicas en individuos de origen americano. No obstante, los visitantes a través de sus comentarios no realizaron una distinción entre la preferencia de ver huesos reales o réplicas, aún cuando en los nomencladores de la exhibición se realiza la aclaración.

En este contexto, cerca de las dos terceras partes de los visitantes se mostró a favor de las políticas institucionales de no exhibir restos de poblaciones americanas, contra un $30 \%$ de encuestados en contra y $7 \%$ que no tomó posición (Tabla 9). Es de destacar que dichas opiniones a favor y en contra fueron independientes de la curiosidad por los restos humanos. Esto significa que aún los visitantes que tuvieron preferencia por la observación y conocimiento de las momias y esqueletos, manifestaron su acuerdo con que se retiren de la exhibición aquellos sobre los que pesaba la solicitud de no exhibir, postergando o dejando en segundo plano su propio interés. Tampoco se pudo detectar una relación directa entre el acuerdo o desacuerdo de no exhibir y el conocimiento de las leyes de restitución que, indirectamente, respaldan estas decisiones. Esto nos lleva a reflexionar acerca de la autoridad que tiene el museo y el poder que ejerce en la formación de opinión en el público general, a la vez que nos aproximamos a una consideración positiva en cuanto a la evaluación de la exhibición, acercando la opinión del público a los objetivos perseguidos.

La encuesta realizada incluyó la indagación acerca del por qué del acuerdo/desacuerdo con las políticas institucionales, a través de una pregunta abierta. Si bien las respuestas registradas serán motivo de un análisis de tipo cualitativo, es posible, hasta el momento, anticipar la aparición en el discurso de ciertos patrones de asociación. Quienes manifestaron desacuerdo por el retiro de los restos americanos de la exhibición adujeron como causa principal el deseo de conocer, saber (acerca de) y ver dichos restos. Las personas que acordaron con las políticas institucionales manifestaron frecuentemente el respeto (tanto por los muertos como por los miembros de las comunidades aborígenes) y la consideración de sus deseos. En concordancia con estas opiniones, el estudio de Alberti et al. (2009) presenta una síntesis de un debate entre investigadores acerca de la exhibición de restos humanos. Los científicos a favor argumentaron que la exhibición contribuye a estimular el interés en la ciencia y en el modo en que los cuerpos informan acerca del pasado. Aquellos investigadores que estuvieron en contra de las exhibiciones consideraron, entre otros aspectos, los deseos de los muertos y la falta de consentimiento para que sus cuerpos permanezcan en una exhibición museológica.

Como menciona este mismo autor, "un ítem en exhibición se relaciona con otros ítems y sus curadores, pero también con sus audiencias. Los visitantes observan y reaccionan y sus respuestas son síntomas de la relación entre la cosa y el observador en un vínculo histórico y culturalmente contingente, pero nunca unidireccional" (Alberti 2005: 568-9).

La apertura hacia la incorporación y presencia activa de los grupos históricamente excluidos define al museo como un nuevo espacio de observación y ejercicio de prácticas sociales. Concebidos como "zonas de contacto" la estructura organizativa del museo se vuelve una relación permanente histórica, política y moral (Clifford 1999).

La toma de decisiones en torno de la exhibición de restos humanos y su reflejo en la exposición constituye un proceso en el que intervienen numerosas variables. La confluencia de cuestiones históricas, las recomendaciones internacionales, las formas en que se constituyeron las colecciones, su naturaleza, la identidad y procedencia, las respuestas a los reclamos explícitos por parte de las comunidades y el contexto discursivo en el que son incluidas son solo algunas de las cuestiones a considerar en la gestión de materiales bioantropológicos. Uno de los aportes a esta discusión implica conocer a los visitantes y promover espacios dinámicos para una reflexión actualizada, sin perder de vista que el patrimonio se impregna de los significados que le otorgan quienes lo exponen, quienes lo producen y quienes lo miran.

\section{Agradecimientos}

A los revisores, porque sus comentarios ayudaron a mejorar notablemente este trabajo. A Melisa Auge y Natalia Vera por su participación en la realización de las encuestas. A Analía Martino y Leandro Gianelo por la información institucional proporcionada.

\section{Bibliografía}

Alberti, S.J.M.M. 2005. Objects and the museum. Isis, 96: 559-571.

Alberti, S.J.M.M. 2007. Constructing nature behind glass. Museum and Society, 6: 73-97. 
Alberti, S.J.M.M., P. Bienkowski y M.J. Chapman. 2009. Should we display the dead? Museum and Society, 7: 133-149.

Ametrano, S., 2010. Historia de una restitución. Rev. Museo, Fundación Museo de La Plata "Francisco P. Moreno", 3(24): 61-67.

Arenas, P. 2011. Ahora Damiana es Krygi. Restitución de restos a la comunidad aché de Ypetimi. Paraguay. Corpus. Archivos virtuales de la alteridad americana.

Asensio, M., E. Pol. 1996. Cuando la mente va al museo: un enfoque cognitivo-receptivo de los estudios de público. En: Actas de las IX Jornadas estatales Deac-museos, 83-134. Jaén, España.

Asensio, M., E. Pol. 2002. Nuevos escenarios en educación. Aprendizaje informal sobre el patrimonio, los museos y la ciudad. Aique, Buenos Aires.

Bialogorski, M., A. M. Cousillas. 2000. Gestión cultural y estudios de público en el Museo José Hernández. Cuadernos de Antropología Social, 12: 195-205

Brooks, M. M., C. Rumsey. 2007. The body in the museum. En: Classman, V., N. Odegaard y J. Powell, eds. Human Remains: Guide for museums and academic institutions. Cap. 17, 261-289, Altamira Press, Lanham.

Bourdieu, P., J.D. Wacquant. 1995. Respuestas por una antropología reflexiva. Grijalbo, México.

Cassman, V., N. Odegaard y J. Powell, eds. 2007. Human remains. Guide for museums and academic institutions. Altamira Press, Lanham.

Clifford, J. 1999. Itinerarios transculturales. Gedisa, Barcelona.

Cousillas, A. M. 1997. Los Estudios de Visitantes a Museos. Fundamentos generales y principales tendencias. http://www.geocities. com/emuseoros/Docs/Estudios_visitantes_museo.htm

Cury, M. X. 2005. Comunicação e pesquisa de recepção: uma perspectiva teórico metodológica para os museus. Museus e Ciencias, 12: $365-380$

Eidelman, J. y Roustan M. 2013. Introducción. Estudios de Públicos: investigación básica, elección de políticas y apuestas operativas. Em: El Museo y sus Públicos. El visitante tiene la palabra. Argentina, Ed. Ariel, Fundación TyPA, 2013:20-46)

Endere, M. L. 2011. Cacique Inakayal. La primera restitución de restos humanos ordenada por ley. Corpus. Archivos virtuales de la alteridad americana, 1.

Farro, M. 2009. La formación del Museo de La Plata. Coleccionistas, comerciantes, estudiosos y naturalistas viajeros a fines del siglo XIX. Prohistoria Ediciones, Rosario.

García Blanco, A. 1999. La exposición un medio de comunicación. AKAL, Madrid.

Karp, I. 1991. Culture and Representation. En: Exhibiting Cultures. The poetic and politics of museum display. Part I, 11-25, Smithsonian Institution Press, Washington.

Kelmansky, D.M. 2009. Estadística para todos. Estrategias de pensamiento y herramientas para la solución de problemas. Ministerio de Educación de la Nación, Buenos Aires.

Kilmister, H. 2003. Visitor perceptions of ancient Egyptian human remains in three United Kindom museums. Papers from the Institute of Archaeology, 14: 57-69.

Korn, R. \& Associates. 1999. Responses to a human remains collection: findings from interviews and focus group. http://informalscience.org/ images/evaluation/ report_58.pdf (Última consulta: 20/08/2013)

Lehmann-Nitsche, R. 1910. Catálogo de la Sección Antropología del Museo de La Plata. Coni, Buenos Aires.

Lohman, J., K. Goodnow, eds. 2006. Human remains \& museum practice. Vol 918. United Nations Educational Scientific and Cultural Organization, Barcelona.

Magariños de Morentín, J. 2008. La Semiótica de los Bordes. Apuntes de metodología semiótica. Córdoba. Comunic-Arte. Colección lengua y discurso.

Pérez Santos, M. E. 2000. Estudio de visitantes en museos: metodología y aplicaciones. Trea, Guijón.

Podgorny, I. 1999. La Patagonia como santuario natural de la ciencia finisecular. Redes, 6: 157-176.

Podgorny, I. 2008. Momias que hablan. Ciencia, colección de cuerpos y experiencias con la vida y la muerte en la década de 1880. Prismas, Revista de historia intelectual, 12: 49-65.

Podgorny, I., M. M. Lopes. 2008. El Desierto en una vitrina. Museos e historia natural en la Argentina, 1810-1890. Limusa, Mexico.

Politis, G. 1994. El regreso de Inakayal. Rev. Museo, Fundación Museo de La Plata "Francisco P. Moreno", 1: 46-48.

Pucciarelli, H. M., M. L. Sardi. 2009. La nueva sala de Antropología del Museo de La Plata: el logro de una ambición largamente esperada y finalmente concretada. Revista Museo (Fundación Museo de La Plata), 23: 73-79.

Reca, M. M. 2011. Estudio de público de museos: el aporte teóricometodológico de la semiótica. Revista do Museu de Arqueología e Etnología, 21: 357-369.

Sardi, M. L. 2009. Ser y Pertenecer. Un recorrido por la evolución humana. Museo de La Plata, La Plata.

Sardi, M. L. 2011. Argentina. En: Márquez-Grant, N., L. Fibiger, editores. The Routledge handbook of archaeological human Remains and legislation: an international guide to laws and practice in the excavation, study and treatment of archaeological human remains. Cap 51, 579-583, Taylor and Francis Group, Routledge.

van Duuren, D., M. ten Kate, M. Pereira, S. Vink y S. Legêne. 2007. Physical anthropology reconsidered: human remains at the Tropenmuseum. KIT Tropenmuseum, Amsterdam.

Zar, J. H. 1999. Biostatistical analysis. Prentice Hall, New Jersey.

Zeballos, E. 1960 [1881]. Viaje al país de los araucanos. Hachette, Buenos Aires. 